NBER WORKING PAPER SERIES

OFFSHORING: GENERAL EQUILIBRIUM EFFECTS ON WAGES, PRODUCTION AND TRADE

Richard Baldwin

Frederic Robert-Nicoud

Working Paper 12991

http://www.nber.org/papers/w12991

\author{
NATIONAL BUREAU OF ECONOMIC RESEARCH \\ 1050 Massachusetts Avenue \\ Cambridge, MA 02138 \\ March 2007
}

We thank seminars participants at the National University of Singapore (September 2006), Hitotsubashi University (December 2006), the Paris School of Economics (January 2007), and Oxford (February 2006) for comments, especially Pol Antras, Christopher Bliss, Jota Ishikawa, Ron Jones, Taiji Furusawa, Marc Melitz, Jim Markusen, Peter Neary, Volker Nocke, Thierry Verdier, David Vines, and Adrian Woods. We especially thank Gene Grossman and Estaban Rossi-Hansberg for comments on early drafts in September 2006 and November 2006. The views expressed herein are those of the author(s) and do not necessarily reflect the views of the National Bureau of Economic Research.

(C) 2007 by Richard Baldwin and Frederic Robert-Nicoud. All rights reserved. Short sections of text, not to exceed two paragraphs, may be quoted without explicit permission provided that full credit, including $(\mathrm{C}$ notice, is given to the source. 
Offshoring: General Equilibrium Effects on Wages, Production and Trade

Richard Baldwin and Frederic Robert-Nicoud

NBER Working Paper No. 12991

March 2007

JEL No. F11,F12,F16

\section{ABSTRACT}

A simple model of offshoring, which depicts offshoring as 'shadow migration,' permits straightforward derivation of necessary and sufficient conditions for the effects on wages, prices, production and trade. We show that offshoring requires modification of the four classic international trade theorems, so econometricians who ignore offshoring might reject the Heckscher-Ohlin theorem when a properly specified version held in the data. We also show that offshoring is an independent source of comparative advantage and can lead to intra-industry trade in a Walrasian setting. The model is extended to allow for two-way offshoring between similar nations, and to allow for monopolistic competition.

Richard Baldwin

Cigale 2

CH-1010 Lausanne

SWITZERLAND

and NBER

Baldwin@HEI.UNIGE.CH

Frederic Robert-Nicoud

LSE

Department of Geography and Environment

London WC2A 2AE

United Kingdom

f.1.robert-nicoud@1se.ac.uk 


\title{
Offshoring: general equilibrium effects on wages, production and trade
}

\author{
Richard Baldwin and Fréderic Robert-Nicoud ${ }^{1}$ \\ Graduate Institute of International Studies, Geneva; London School of Economics
}

First draft: November 2006; This version: March 2007

\begin{abstract}
$\underline{\text { Abstract }}$
A simple model of offshoring, which depicts offshoring as 'shadow migration,' permits straightforward derivation of necessary and sufficient conditions for the effects on wages, prices, production and trade. We show that offshoring requires modification of the four classic international trade theorems, so econometricians who ignore offshoring might reject the Heckscher-Ohlin theorem when a properly specified version held in the data. We also show that offshoring is an independent source of comparative advantage and can lead to intra-industry trade in a Walrasian setting. The model is extended to allow for two-way offshoring between similar nations, and to allow for monopolistic competition.
\end{abstract}

\section{INTRODUCTION}

The fragmentation and offshoring of production processes has been an important phenomenon for many years (Hummels, Ishii, and Yi 2001), having started in earnest in the mid-1980s in East Asia and across the US-Mexico border. Ando and Kimura (2005) and Urata (2001), for example, document the linked rise of foreign direct investment, offshoring, and parts and components trade by Japanese firms in East Asia. In North America, the 1980s saw the widespread emergence of 'twin plants' (one on either side of the US-Mexico border) under the Maquiladora programme (Dallas Fed 2002, Feenstra and Hanson 1996). More recently, offshoring has spread from the manufacturing to the service sector (Amiti and Wei 2005).

The observed empirical effects of offshoring do not sit easily with simple partial equilibrium models that view one job shifted overseas as one job lost. For example, in both the US and Japanese cases, the widespread offshoring of manufacturing jobs that started in the mid-1980s was not accompanied by a general decline in manufacturing employment until the late 1990s (Debande 2006). Likewise, two recent studies of micro data find that expansion of employment in affiliates in low income countries raises the skill intensity of domestic production (see Head and Ries 2002 on Japanese data and Geishecker and Gorg 2004 on German data). Understanding such effects requires a general equilibrium framework where wages, prices, production and trade patterns adjust to offshoring. Responding to this need, some of the world's best trade economists have put forth general equilibrium models of offshoring/fragmentation. As we argue in the sequel, these models can be viewed as a collection of insightful special cases. In addition, many of them have a complex structure that forced their authors to rely on numerical simulations to study their equilibrium properties.

\footnotetext{
${ }^{1}$ We thank seminars participants at the National University of Singapore (September 2006), Hitotsubashi University (December 2006), the Paris School of Economics (January 2007), and Oxford (February 2006) for comments, especially Pol Antras, Christopher Bliss, Jota Ishikawa, Ron Jones, Taiji Furusawa, Marc Melitz, Jim Markusen, Peter Neary, Volker Nocke, Thierry Verdier, David Vines, and Adrian Woods. We especially thank Gene Grossman and Estaban RossiHansberg for comments on early drafts in September 2006 and November 2006.
} 


\section{Our model}

The purpose of our paper is to present a simple model of offshoring that enables us to develop necessary and sufficient conditions for signing the wage, price, production and trade effects of offshoring in source and host countries. Our baseline model finds firms in all sectors unbundling the production process and putting fragments of it abroad to take advantage of low-cost foreign factors of production. Importantly, our model avoids the analytic complexity of multi-cone models and factorintensity reversals. Non-factor-price-equalisation exists under free trade due to Hicks-neutral technological differences among nations. Despite the resulting effective factor price equalisation, offshoring by the technologically advanced nation is cost-saving since offshoring firms can take their superior technology with them when they shift production abroad. ${ }^{2}$ Since neither nation is specialised in production, our baseline model can be studied in the familiar setting of Jones (1965) and this allows us to consider a wide range of effects including the impact of offshoring on the four theorem of Heckscher-Ohlin trade theory. In particular, we show that offshoring leads to intra-industry trade in a perfectly competitive, Heckscher-Ohlin-like setting and that offshoring is, by itself, a source of comparative advantage. The general equilibrium incidences on production, prices and wages are shown to be ambiguous in general and we characterise the factors that lead the ambiguity to resolve itself in one direction or the other. Importantly, we find that the factor owners of the offshoring nation are typically better off as a result of fragmentation (controlling for terms of trade effects).

We work with two main variants of the basic model. In the first, which we call the service-task case (mostly for terminological convenience), all offshored production is re-imported to the Home nation. In the second, which we call the goods-task case, local sales are possible in the sense that offshore production units can supply Foreign firms as well as Home firms. In the goods-task case, the gains from offshoring are shared between nations and factor within nations, while in the service-task case Foreign wages are unaffected by offshoring (apart from possible terms of trade effects).

Finally, we provide two simple model extensions. The first allows for two-way intra-industry offshoring - an important extension since the largest importers and exporters of offshored services are the United States and other large OECD countries (Amiti and Wei 2005). The second allows for offshoring in a monopolistic competition model where the notion of a firm is better defined than it is in the Walrasian setting (but comparison with the four Heckscher-Ohlin (HO) theorems is less evident).

\section{The literature}

Early on, Heckscher-Ohlin theory saw a number of contributions that incorporated trade in intermediate goods (see Batra and Casas 1973, Woodland 1977, and Dixit and Grossman 1982), but the most commonly cited reference in the offshoring/fragmentation literature is Jones and Kierzkowski (1990). The Jones-Kierzkowski paper crystallised the insight that fragmentation/offshoring can be thought of as technological progress and thus should be expected - as per Jones (1965) - to have complex effects. This line of modelling - which includes Jones and Marjit (1992), Arndt (1997, 1999), Jones and Findlay (2000, 2001), Jones and Kierzkowski (1998, 2000), and Jones, Kierzkowski and Leonard (2002) - is based on verbal and diagrammatic analysis (typically of small open economies) that assumes fragmentation occurs in only one sector and in one direction. See Francois $(1990 \mathrm{a}, \mathrm{b}, \mathrm{c})$ for formal, general-equilibrium modelling of the central mechanism in the Jones-Kierzkowski fragmentation story - the way in which the liberalisation of service links can promote the fragmentation of production blocks. ${ }^{3}$

The general equilibrium impact of Jones-Kierzkowski fragmentation varies according to the special case considered, with cases varying along three main dimensions: the factor intensity of the sector that

\footnotetext{
${ }^{2}$ This assumption follows the Section 3.2 model in Grossman and Rossi-Hansberg (2006b), August 2006 version.

${ }^{3}$ Francois (1990c) explicitly considers the impact of offshoring on the factor price equalization set.
} 
is fragmented, the factor intensity of the process that is offshored, and the offshoring nation's relative endowment. The Jones and Kierzkowski (1998) diagrammatic analysis yields examples that suggest two important insights - what might be called the "Jones ambiguity" and the "anti-Stolper-Samuelson possibility." Using a pair of special cases, Jones and Kierzkowski (1998) argue that workers whose jobs are "lost" to offshoring may see their wages rise in one case, but fall in the other. ${ }^{4}$ The "antiStolper-Samuelson" insight, which stems from viewing fragmentation as technological progress, notes that freer offshoring/fragmentation - unlike freer trade in goods - need not produce winners and losers among factor owners. ${ }^{5}$

Contributions that study the price, wage, production and trade effects of offshoring in explicit mathematical models include Deardorff (1989a, b), Venables (1999), Kohler (2004a), Markusen (2005), and Grossman and Rossi-Hansberg (2006a,b). These papers present a gallery of special cases that firmly establish the ambiguous sign of the general equilibrium price, production, trade and factor price effects. A linchpin issue facing all general equilibrium models in this literature is the question of how offshoring can be cost-saving when international trade in goods naturally leads to factor price equalisation. To address this issue, these papers work in models marked by non-factor price equalisation. Since non-factor price equalisation typically prevents utilisation of the elegant Jones (1965) tools, the analysis in these papers is quite complex. Most of these authors also assume that offshoring/fragmentation occurs in only one sector and only in one direction (to keep the analysis manageable).

Deardorff $(1989 a, b)$ studies fragmentation in a range of explicit models using graphical analysis. The main formal analysis, however, concerns a HO setting where cost-saving offshoring occurs since nations' endowments are assumed to lie in different diversification cones. Deardorff (1989a) argues that fragmentation/offshoring may or may not foster factor price convergence. Working with LernerPearce diagrammatic analysis of a general model with fragmentation in a single sector, he notes "if you accept this argument, then such a move toward factor price equality is not at all assured. It depends crucially on ... the factor intensities both of the fragments and of the original technology. There are many possibilities, including that relative factor prices move in the same direction in both countries and that they both move either together or further apart. (p. 14)" Necessary and sufficient conditions are not established. He then moves to explicit mathematical analysis using a 2-nation, 2factor, many-good, multi-cone HO model with Cobb-Douglas tastes and technology. He derives explicit expressions for relative factor prices in the two nations, showing that the wage ratios depend upon the national capital-labour ratios and national weighted average of the factor intensity of produced goods. Fragmentation changes the latter and can thus lead to a convergence or divergence of relative factor prices (no expressions are given for the level of factor prices). The paper concludes by noting that "the effects on relative factor prices in the countries where the fragmentation takes place depend fairly systematically on the factor intensities of the fragments, as well as that of the original technology. What matters, however, is how these factor intensities compare to the average intensities of processes in use in each country before fragmentation, not their intensities compared to all goods produced globally." Necessary and sufficient conditions for relative factor price convergence are not derived but are implicit in the expressions.

Venables (1999) works with a standard 2x2x2 HO model and generates non-factor-price equalisation with a factor intensity reversal. Nations can thus have different factor prices without being specialised

\footnotetext{
${ }^{4}$ Referring to a HO model with capital and labour, Jones and Kierzkowski (1998, p. 373) write: "the charge that if international trade causes a nation to lose a production activity which is intensive in the use of labour, it will cause the wage to fall, need not be true - especially for relatively capital-abundant nations."

${ }^{5}$ Jones and Kierzkowski (1998, p. 380) write: "But even here the prognosis for a nation's labour supply need not be gloomy, since such fragmentation tends as well to work like technical progress in raising the returns to all factors."
} 
in production. As in the Jones-Kierzkowski tradition, fragmentation occurs in only one industry and offshoring occurs in only one direction (the labour-intensive segment is offshored to the labour abundant nation). Using numerical simulations and Lerner-Pearce diagrammatic analysis, he concludes that "production fragmentation does not necessarily lead to convergence of factor prices," and provides examples of both cases without developing necessary and sufficient conditions. The paper goes on to note that "fragmentation may change factor prices by changing the composition of Home exports, as well as imports" and that "it is possible to generate some curious cases in which it is the relatively capital intensive industry, not the labour intensive which leaves Home for Foreign," (curious since Home is capital-rich).

Kohler (2004a) works with a specific factors model where fragmentation can only occur in one sector. Discussion of the source of non-factor price equalisation is avoided by assuming a small open economy where all goods prices and Foreign wages are immutably fixed (in the Jones-Kierzkowski tradition). The focus of the analysis is on the reward to the specific capital that moves offshore when fragmentation occurs, and the overall welfare effects on the small open economy.

Markusen (2005) works with a 2x2x2 HO model where one sector fragments, and he, like Deardorff, generates non-factor-price equalisation by assuming the two nation are in different diversification cones (i.e. their endowments are so different that they produce no goods in common in equilibrium). Analytic results with multi-cone models are difficult (due to the inequality constraints), so the paper studies offshoring/fragmentation via numerical simulations based on the complementary slackness approach. Fragmentation is assumed to occur in the skill-intensive sector and the offshored segment is assumed to be of middling skill-intensity. Offshoring therefore tends to increase the relative demand for skilled labour - and thus the skill premium - in both nations, but terms of trade effects can depending upon the nations' relative sizes - reverse this direct effect. One of the numerical simulations even shows the possibility of both factors losing in the offshoring nation (necessary and sufficient conditions are not established). Another simulation shows an anti-Stolper-Samuelson result whereby the skilled workers in the unskilled-labour-rich nation gain from offshoring in an absolute sense, but they gain less than their fellow unskilled workers. Markusen (2005) points out the limitation of the analysis: "In spite of doing countless runs of this model, I cannot guarantee that there are not other possibilities and, of course, reordering the factor intensities will change the results. What I can say is that it is easy to find ranges of parameters that generate these results, but we should all regard them as suggestive and not definitive." The paper goes on to simulate four other models that vary in terms of the number of factors, the substitutability of factors in various sectors, and the factor-intensity of the offshored process and offshoring sector. The paper closes by noting "I view the paper as listing a number of plausible and empirically-relevant ways of modelling the offshoring of white-collar services... Unfortunately, it is hard to offer robust conclusions."

Kohler (2004b) works with a small open economy where fragmentation/offshoring can only happen in one sector. He departs from other models, however, in using a radically different production structure - that of Dixit and Grossman (1982) where final good production involves of continuum of intermediate stages, each of which requires capital and labour. The production stages are strict complements in that producing the final good requires each one to be performed in fixed proportions. At the cost of additional assumptions on the capital intensity of upstream versus downstream stages of production, the Dixit-Grossman production structure yields a very simple characterisation of the endogenous range of stages that are offshored given an exogenously specified range of offshoring costs for each stage of production. The focus of his analysis is on establishing a 'generalised factor price frontier' that takes account of the shifts in the range of stages that are offshored when prices or offshoring costs change exogenously. When prices change, he shows that offshoring can heighten or dampen the magnification aspect of the Stolper-Samuelson effects. He also shows that cheaper offshoring produces more offshoring and this raises or lowers factor prices according to the relative 
factor intensity of the two sectors and the fragments offshored. No formal results are presented on production and trade effects.

More recently, Grossman and Rossi-Hansberg (2006a,b) - GRH for short - present a formal model where the wage effects of offshoring are unambiguous. GRH (2006a), for example, highlights the case where offshoring unambiguously raises the wage of workers whose jobs are offshored (controlling for terms of trade effects). The unambiguous effect is driven by the fact that offshoring acts a technological progress - what they call the productivity effect. Grossman and Rossi-Hansberg (2006b) explore the issues in greater depth, confirming the unambiguous productivity effect on wages in certain cases. GRH also identify an anti-Stolper-Samuelson effect. As they argue (using 'trade in tasks' as a synonym for offshoring): "reductions in the cost of trading tasks can generate shared gains for all domestic factors, in contrast to the distributional conflict that typically results from reductions in the cost of trading goods. (GRH 2006b, abstract)" GRH present an array of models to illustrate their findings, but the common core of their models is a technological specification akin to the Dixit and Grossman (1982) model. Unlike Kohler (2004b), however, the stages (called 'tasks') require only unskilled labour ( $L$-tasks) or only skilled labour $(H$-tasks). Substitution between the $L$-task and $H$-task continuums is possible, but $L$-tasks are strict complements in that producing the final good requires each task to be performed in fixed proportions; the same holds for $H$-tasks.

\section{Organisation of paper}

The next section, Section 2, presents a simplified HO model and briefly lays out the four standard trade theorems in order to fix ideas and introduce notation. The next section presents our model of offshoring, characterises the equilibrium, and then shows how offshoring requires a modification of the four standard trade theorems. Section 3 presents our extensions. The final section presents our concluding remarks.

\section{TRADE IN GOODS IN A MODIFIED HO MODEL}

To introduce our notation and normalisations, we introduce the familiar $2 \times 2 \times 2 \mathrm{HO}$ model and demonstrate the four theorems. The model assumes two nations, Home and Foreign, two final goods, $X$ and $Y$, and two primary factors, human capital $(K)$ and labour $(L)$. Tastes are homothetic and identical across nations; Foreign is relatively abundantly endowed with labour and $Y$ is the $K$-intensive good:

$$
\kappa_{Y}>\kappa_{X} ; \quad \kappa_{Y} \equiv \frac{a_{K Y}}{a_{L Y}}, \quad \kappa_{X} \equiv \frac{a_{K X}}{a_{L X}}
$$

where $\kappa_{i}$ is the capital intensity of sector- $i$ and the Leontief $a_{i j}$ 's employ the standard factor- and sectorsubscript notation.

Home is assumed to be technologically superior in the Hicks-neutral sense (Davis 1995, Trefler 1993). Specifically, all Foreign unit input requirements are $\gamma>1$ times higher than Home's. Since $a_{i j}{ }^{*}=\gamma a_{\mathrm{ij}}$ (“*”" indicates Foreign variables), (1) also holds for Foreign technology. Note that the Hicks-neutral technology differences do not give rise to Ricardian motives for trade in our model. Indeed, we can mechanically transform the model into a standard HO model by defining Foreign factor supplies in 'effective units', i.e. dividing $L^{*}$ and $K^{*}$ by the technological-inferiority-factor $\gamma$.

In autarky, the Home or Foreign equilibriums are characterised by two pricing equations, two employment equations and a market clearing condition. The pricing equations in the two nations are: ${ }^{6}$

\footnotetext{
${ }^{6}$ In general, these should be inequalities; we use equalities since we assume that parameters are such that both nations' production structures are diversified at the sectoral level with free trade, i.e. they share a diversification cone. This requires them to have sufficiently similar endowment ratios, in a way that we formalise in the sequel.
} 


$$
\left[\begin{array}{l}
1 \\
p
\end{array}\right]=\mathbf{A}^{\mathrm{T}}\left[\begin{array}{l}
w \\
r
\end{array}\right], \quad\left[\begin{array}{c}
1 \\
p^{*}
\end{array}\right]=\gamma \mathbf{A}^{\mathrm{T}}\left[\begin{array}{c}
w^{*} \\
r^{*}
\end{array}\right] ; \quad \mathbf{A}^{\mathrm{T}} \equiv\left[\begin{array}{cc}
a_{L X} & a_{K X} \\
a_{L Y} & a_{K Y}
\end{array}\right]
$$

where $X$ is numeraire, $p$ denotes the price of $Y, w$ and $r$ are the rewards for unskilled labour $(L)$ and skilled labour $(K)$, respectively (' $\mathrm{T}$ ' indicates the matrix transpose). The employment equations are:

$$
\left[\begin{array}{l}
L \\
K
\end{array}\right]=\mathbf{A}\left[\begin{array}{l}
X \\
Y
\end{array}\right], \quad\left[\begin{array}{c}
L^{*} \\
K^{*}
\end{array}\right]=\gamma \mathbf{A}\left[\begin{array}{c}
X * \\
Y^{*}
\end{array}\right]
$$

Market-clearing conditions for Home and Foreign in autarky, and the world (with free trade) are:

$$
\frac{p Y}{X}=\frac{\alpha E}{(1-\alpha) E}, \quad \frac{p^{*} Y^{*}}{X^{*}}=\frac{\alpha E^{*}}{(1-\alpha) E^{*}}, \quad \frac{p Y^{w}}{X^{w}}=\frac{\alpha E^{w}}{(1-\alpha) E^{w}}
$$

with Cobb-Douglas preferences ( $\alpha$ is $Y^{\prime}$ s expenditure share). The E's are GDP (expenditure) in terms of the numeraire. ${ }^{7}$

\subsection{Free trade in goods and the 4 theorems}

Assuming neither nation specialises, (2) and (3) yield the equilibrium wages and outputs:

$$
\left[\begin{array}{l}
w \\
r
\end{array}\right]=\left(\mathbf{A}^{\mathbf{T}}\right)^{-1}\left[\begin{array}{l}
1 \\
p
\end{array}\right], \quad\left[\begin{array}{l}
w^{*} \\
r^{*}
\end{array}\right]=\frac{1}{\gamma}\left(\mathbf{A}^{\mathbf{T}}\right)^{-1}\left[\begin{array}{l}
1 \\
p
\end{array}\right], \quad\left[\begin{array}{l}
X \\
Y
\end{array}\right]=\mathbf{A}^{-1}\left[\begin{array}{c}
L \\
K
\end{array}\right], \quad\left[\begin{array}{l}
X^{*} \\
Y^{*}
\end{array}\right]=\frac{1}{\gamma} \mathbf{A}^{-1}\left[\begin{array}{c}
L^{*} \\
K^{*}
\end{array}\right]
$$

Autarky and free trade equilibrium factor prices, which follow from (5) and (4), are:

Autarky: $\quad p=\frac{\alpha /(1-\alpha)}{a_{L X} / a_{L Y}}\left(\frac{\kappa_{Y}-k}{k-\kappa_{X}}\right), \quad p^{*}=\frac{\alpha /(1-\alpha)}{a_{L X} / a_{L Y}}\left(\frac{\kappa_{Y}-k^{*}}{k^{*}-\kappa_{X}}\right)$

Trade: $\quad p=\frac{\alpha /(1-\alpha)}{a_{L X} / a_{L Y}}\left(\frac{\kappa_{Y}-\tilde{k}^{w}}{\tilde{k}^{w}-\kappa_{X}}\right)$

where the lower-case $k^{\prime}$ s are national endowment ratios, i.e. $k \equiv K / L$ and $k^{*} \equiv K^{*} / L^{*}$ and $\tilde{k}^{w}$ is the world capital-labour ratio measured in effective units, namely $\tilde{k}^{w} \equiv\left(K+K^{*} / \gamma\right) /\left(L+L^{*} / \gamma\right)$. We use “ " to denote factor supplies measured in effective units. The non-specialisation regularity condition - i.e. $\kappa_{X}<k^{*}<\tilde{k}^{w}<k<\kappa_{Y}-$ implies that all endogenous variables are positive in equilibrium.

The Factor Price Equalisation (FPE) theorem states that free trade equalises factor prices internationally by equalising goods prices. Here the FPE theorem holds but for 'effective' units of factors, i.e. counting an hour of Foreign labour as $1 / \gamma$ times an hour of Home labour. From (5), the international ratio of wages in terms of the numeraire is $\gamma$.

The Heckscher-Ohlin (HO) theorem states that the relatively $L$-rich nation exports the $L$-intensive good and imports the $K$-intensive good. Home imports of $X$, using (5) and (6), are:

$$
M_{X}=\frac{\alpha L}{a_{L X}}\left(\frac{k-\tilde{k}^{w}}{\tilde{k}^{w}-\kappa_{X}}\right)
$$

\footnotetext{
${ }^{7}$ Specifically, preferences are given by $U=X^{1-\alpha} Y^{\alpha}$ and $E=X+p Y=w L+r K$ in Home, with an isomorphic definition for $E^{*}$. The loss of generality that results from assuming a specific functional form for preferences is more than compensated by the two following facts: first, this assumption is not necessary to generate any of our general results regarding the effects on factor prices and production patterns. Second, it allows us to derive explicit closed-form solutions for equilibrium terms-oftrade and trade volumes; the qualitative effects would remain unchanged if we allowed for general homothetic preferences.
} 
where $M_{X}$ is our notation for Home imports of $X$. Since the denominator is positive (the world's endowment is within the diversification cone), Home imports the $L$-intensive good if and only if its capital-labour endowment ratio exceeds the world's effective capital-labour endowment ratio. This demonstrates the Heckscher-Ohlin theorem since trade balance implies that the value of Home's exports of $Y$ equals $-M_{X}$.

The Stolper-Samuelson theorem is a partial equilibrium result ( $p$ is exogenous) that connects goods and factor prices; a rise in the price of the $K$-intensive good raises $r$ more than proportionally and lowers $w$. This can be seen from log differentiation of the solution for $w$ and $r$ in (5):

$$
\frac{d w / w}{d p / p}=\frac{-p}{a_{K Y} / a_{K X}-p}<0, \quad \frac{d r / r}{d p / p}=\frac{p}{p-a_{L Y} / a_{L X}}>1
$$

This means that $r$ rises more than proportionally with $p$ and $w$ actually falls, so qualitatively the $w$ and $r$ changes are like real wage changes. (The inequalities follow from our factor intensity assumptions as usual.)

The Rybczynski theorem is a partial equilibrium result ( $p$ is exogenous) which states, in its simple form, that a rise in a nation's endowment of $L$ raises its production of the $L$-intensive good more than proportionally and lowers its production of the other good. Log differentiating (5):

$$
\frac{d X / X}{d L / L}=\frac{\kappa_{Y}}{\kappa_{Y}-k}>1, \quad \frac{d Y / Y}{d L / L}=\frac{-\kappa_{X}}{k-\kappa_{X}}<0
$$

\section{A SIMPLE MODEL OF THE OFFSHORING}

This section modifies the HO model to allow for offshoring/fragmentation. We model the production of $X$ as involving three "tasks" labelled $X 1, X 2$ and $X 3$, which can be thought of segments of the production process (in which case the task's output is an intermediate good) or service inputs. Likewise, $Y$ production involves tasks $Y 1, Y 2$ and $Y 3$. In the HO model, the tasks were bundled into $a_{L X}$ and $a_{K X}$. Here we allow them to be unbundled and their production potentially placed abroad, i.e. offshored. Each task involves some $L$ and $K$, so the $a_{i j}$ 's can be decomposed into task-by-task Leontief unit input coefficients:

$a_{L X} \equiv a_{L X 1}+a_{L X 2}+a_{L X 3}, \quad a_{K X} \equiv a_{K X 1}+a_{K X 2}+a_{K X 3}$

where the $L$ and $K$ unit inputs for task- $i$ in sector $j$ denotes as $a_{L j i}$ and $a_{K j i}$. The coefficients for $Y$ are decomposed into task requirements in an isomorphic manner. In the spirit of the HO model, the international transportation of the fruit of each task is costless.

A key to offshoring is our assumption that firms that offshore a task (i.e. place its production abroad) can combine their own nation's technology with labour in the other nation, paying the local wage rather than workers' marginal products. In this way, offshoring from the high-technology/high-wage nation to the low-technology/low-wage nation may be economic despite the effective factor price equalisation. Offshoring from the low-technology nation to the advanced-technology nation, by contrast, will never be economic.

While offshoring tends to reduce costs, it may not occur if the cost of coordinating spatially separated tasks is too great. To be explicit about the coordination costs and the nature of tasks, we assume that individual tasks are not equally easy to separate spatially from the other two tasks. We model the coordination costs as being of the iceberg type. That is, production of a unit of $X 1$ by a Home firm in Foreign requires $\chi(X 1) a_{L X 1}$ and $\chi(X 1) a_{K X 1}$ units of $L$ and $\mathrm{K}$, where $\chi(X 1) \geq 1$. Note that is as if offshoring causes deterioration in the offshoring firm's production technology (due to the extra coordination costs). $\chi(i)$ varies according to the task and, without loss of generality, we order the tasks 
such that task $X 1$ is the cheapest to offshore, $X 2$ the next cheapest and $X 3$ the most expensive. We impose an isomorphic ordering on $Y$-sector tasks.

The per-unit offshoring costs $\chi$ relates to the cost of coordinating spatially separate tasks within the same firm. In addition, depending upon the nature of the task, it may be much harder to coordinate the three tasks when tasks are performed by different firms - especially when the task involves firmspecific services, many of which may be idiosyncratic, such as accounting services (which involves firm-specific peculiarities) or telephone help-lines (which involve firm-specific training). While it is possible to model this decision more precisely, doing so would make it difficult to compare offshoring with traditional trade in goods. This leads us to introduce an extra set of coordination-cost parameters that simplify the problem. It costs $\chi(X 1)$ to offshore task $X 1$ to Foreign when tasks $X 2$ and $X 3$ are undertaken by the same firm in Home, but is costs $\zeta(X 1)$ to coordinate the three tasks when task $X 1$ is done in a separate firm from task $X 2$ and $X 3$ - and this regardless of whether they are undertaken in the same nation. (The same holds for all the other tasks.) $)^{8}$

For the sake of analytic clarity, we consider two cases. The first case takes the $\zeta$ s as sufficiently high to make inter-firm trade in tasks uneconomical. Thus even if Home firms offshore task $X 1$ to Foreign, they will not supply task $X 1$ to Foreign producers. The second takes the $\zeta$ s as zero so inter-firm trade in tasks becomes economical. For the sake of terminological clarity, we refer to the first case (i.e. no local sales of offshored production) as offshoring of the service-tasks case (although it could also hold for the offshoring of some firm-specific intermediate goods) and the second case (i.e. local sales as economical) as manufacturing-tasks case.

\section{Deviation analysis: Service task offshoring}

To find conditions under which offshoring occurs, we examine the problem facing an atomistic Home $X$ producer that is considering offshoring a task, when no offshoring is yet occurring. Since no offshoring has occurred in this thought-experiment, but trade in goods is free, the analysis from the previous section implies that the low- and high-skill wage gap will be $\gamma\left(\right.$ i.e. $w=w^{*} \gamma$ and $\left.r=r^{*} \gamma\right)$. Offshoring is economical if:

$$
w a_{L X 1}+r a_{K X 1}>\frac{w a_{L X 1}+r a_{K X 1}}{\gamma} \chi(X 1) \quad \Leftrightarrow \quad \gamma>\chi(X 1)
$$

where the first sum is marginal cost of task $X 1$ without offshoring and the second is marginal cost with offshoring, i.e. when the Home firm uses Home technology but pays Foreign factor prices, taking account of the iceberg coordination costs. Plainly, task $X 1$ is offshored only if $\gamma>\chi(X 1)$.

Many cases can arise since the firm might want to offshore tasks $X 1$ and $X 2$, or $X 2$ and $X 3$, or $X 1$ and $X 3$, or even $X 1, X 2$ and $X 3$. To work through all of these, we would have to detail the coordination costs of each proposed bundle and this could be complex since coordination costs are unlikely to be separable. Since the purpose here is to illustrate the fact that offshoring (i.e. trade in tasks) leads to some outcomes that are very different than those obtained with only trade in goods, we discipline the range of cases by making restrictive assumptions. Specifically, we assume that when trade in both goods and tasks is allowed, the coordination costs for $X 1$ and $Y 1$ are nil while the coordination costs of offshoring $X 2, X 3, Y 2$ and $Y 3$ are prohibitive.

Given this simplifying assumption, the atomistic Home firm would find it profitable to offshore task $X 1$ to Foreign. Moreover, an atomistic Home firm in the $Y$ sector would also find it profitable to offshore tasks $Y 1$ to Foreign. Of course, other firms would follow and the re-organisation of work

\footnotetext{
${ }^{8}$ Section 5.2 shows our results all got through in a monopolistic competition trade model where firms are well-defined; we stick with the HO setting to improve comparison with the four theorems and the main offshoring/fragmentation literature.
} 
would change prices, wages, production patterns and trade. We turn to working out the new international equilibrium with free trade in both tasks and goods. Note that Foreign firms would never offshore to Home since this would involve combining inferior Foreign technology with expensive Home factors of production.

\subsection{Service task offshoring}

As discussed above, we roughly associate service-sector offshoring with the case where all offshore production is re-imported to Home because no $X 1$ or $Y 1$ can be sold to Foreign firms by assumption. Given that tasks $X 1$ and $Y 1$ are offshored, the new employment and pricing equations are:

$$
\begin{array}{ll}
{\left[\begin{array}{l}
\mathrm{L} \\
\mathrm{K}
\end{array}\right]=\left(\mathbf{A}-\mathbf{A}_{1}\right)\left[\begin{array}{l}
\mathrm{X}_{\mathrm{O}} \\
\mathrm{Y}_{\mathrm{O}}
\end{array}\right],} & {\left[\begin{array}{c}
1 \\
\mathrm{p}_{\mathrm{O}}
\end{array}\right]=\left(\mathbf{A}^{\mathbf{T}}-\mathbf{A}_{1}^{\mathbf{T}}\right)\left[\begin{array}{c}
\mathrm{w}_{\mathrm{O}} \\
\mathrm{r}_{\mathrm{O}}
\end{array}\right]+\mathbf{A}_{1}^{\mathbf{T}}\left[\begin{array}{c}
\mathrm{w}_{O}^{*} \\
\mathrm{r}_{O}^{*}
\end{array}\right]} \\
{\left[\begin{array}{l}
\mathrm{L}^{*} \\
\mathrm{~K}^{*}
\end{array}\right]=\gamma \mathbf{A}\left[\begin{array}{c}
\mathrm{X}_{O}^{*} \\
\mathrm{Y}_{O}^{*}
\end{array}\right]+\mathbf{A}_{1}\left[\begin{array}{l}
\mathrm{X}_{\mathrm{O}} \\
\mathrm{Y}_{\mathrm{O}}
\end{array}\right],} & {\left[\begin{array}{c}
1 \\
\mathrm{p}_{\mathrm{O}}
\end{array}\right]=\gamma \mathbf{A}^{\mathbf{T}}\left[\begin{array}{c}
\mathrm{w}_{O}^{*} \\
\mathrm{r}_{O}^{*}
\end{array}\right]}
\end{array}
$$

where the subscript ' $O$ ' (for 'offshoring') indicates equilibrium variables with offshoring, and

$$
\mathbf{A}_{1} \equiv\left[\begin{array}{ll}
\chi(X 1) a_{L X I} & \chi(Y 1) a_{L Y I} \\
\chi(X 1) a_{K X 1} & \chi(Y 1) a_{K Y 1}
\end{array}\right]
$$

The pricing equations for Foreign are unaltered by the offshoring (Foreign firms continue to use Foreign technology and Foreign labour as before). When we work with explicit solutions for $X, Y, w$ or $r$, we take the coordination costs to be zero, i.e. $\chi(X 1)=\chi(Y 1)=1$.

\section{Shadow migration}

This offshoring-cum-tech-transfer acts like 'shadow migration.' Home firms use some Foreign $L$ and $K$ to produce goods using Home technology just as if the Foreign $L$ and $K$ migrated to Home and worked in the Home $X$ and $Y$ sectors (but got paid the foreign wages). We assume that the shadow migration is not large enough to move 'effective' endowment ratios outside of the diversification cone, so production remains diversified. Rearranging (12), the employment equations are:

$$
\left[\begin{array}{c}
L_{O} \\
K_{O}
\end{array}\right] \equiv\left[\begin{array}{c}
L+\Delta L \\
K+\Delta K
\end{array}\right]=\mathbf{A}\left[\begin{array}{c}
X_{O} \\
Y_{O}
\end{array}\right], \quad\left[\begin{array}{c}
L^{*}-\Delta L \\
K^{*}-\Delta K
\end{array}\right]=\gamma \mathbf{A}\left[\begin{array}{c}
X_{O}^{*} \\
Y_{O}^{*}
\end{array}\right], \quad\left[\begin{array}{c}
\tilde{L}_{O}^{w} \\
\tilde{K}_{O}^{w}
\end{array}\right]=\mathbf{A}\left[\begin{array}{c}
X_{O}^{w} \\
Y_{O}^{w}
\end{array}\right]
$$

where

$$
\left[\begin{array}{c}
\Delta L \\
\Delta K
\end{array}\right] \equiv \mathbf{A}_{1}\left[\begin{array}{c}
X_{O} \\
Y_{O}
\end{array}\right]>\mathbf{0} ; \quad \tilde{L}_{O}^{w} \equiv L+\frac{L^{*}}{\gamma}+\left(1-\frac{1}{\gamma}\right) \Delta L, \quad \tilde{K}_{O}^{w} \equiv K+\frac{K^{*}}{\gamma}+\left(1-\frac{1}{\gamma}\right) \Delta K
$$

defines the equilibrium amounts of the shadow migration, $\Delta L$ and $\Delta \mathrm{K}$, and the world shadow effective endowments with offshoring. (For closed form solutions, see Appendix.) The definitions of $\tilde{L}_{O}^{w}$ and $\tilde{K}_{O}^{w}$ make it clear that offshoring is like an expansion in the world supply of factors (measured in effective units). The shadow migration amounts, $\Delta L$ and $\Delta K$, are positive given our regularity condition that stipulates that production remain diversified in both nations even after offshoring.

Shadow-migration shows up in the price equations in (12) as cost-savings. For Home and Foreign:

$$
\left[\begin{array}{c}
1+S_{X} \\
p_{O}+S_{Y}
\end{array}\right]=\mathbf{A}^{\mathbf{T}}\left[\begin{array}{c}
w_{O} \\
r_{O}
\end{array}\right], \quad\left[\begin{array}{c}
1 \\
p_{O}
\end{array}\right]=\gamma \mathbf{A}^{\mathbf{T}}\left[\begin{array}{c}
w_{O}^{*} \\
r_{O}^{*}
\end{array}\right], \quad\left[\begin{array}{c}
S_{X} \\
S_{Y}
\end{array}\right] \equiv \mathbf{A}_{1}^{\mathbf{T}}\left[\begin{array}{c}
w_{O}-w_{O}^{*} \\
r_{O}-r_{O}^{*}
\end{array}\right]
$$

where $S_{X}$ and $S_{Y}$ are the per-unit cost savings in the $X$ and $Y$ sectors, respectively. 


\subsubsection{General equilibrium incidence on prices, wages, output and trade}

We turn now to determination of the post-offshoring prices, wages, output and trade flows.

Price effects. Solving (13) for $X_{O}^{w}$ and $Y_{O}^{w}$, and using the market-clearing condition, the postoffshoring price is:

$$
p_{O}=\frac{\alpha /(1-\alpha)}{a_{L X} / a_{L Y}}\left(\frac{\kappa_{Y}-\tilde{k}_{O}^{w}}{\tilde{k}_{O}^{w}-\kappa_{X}}\right)
$$

Comparing this to (6), we see that $Y$ becomes dearer $\left(p_{O}>p\right)$, if and only if shadow migration lowers the world effective capital-labour ratio, i.e. $\tilde{k}_{O}^{w}<\hat{k}^{w}$. From (13), $\tilde{k}_{O}^{w}<\hat{k}^{w}$ holds when the shadow $L$ migration is proportionally greater than shadow $K$-migration (relative to the pre-offshoring world effective labour supplies), i.e. if $\Delta L / \tilde{L}^{w}>\Delta K / \tilde{K}^{w}$. To summarise:

Proposition 1: Offshoring of either type of labour changes the world price of final goods. The relative price of capital-intensive good $Y$ rises if the shadow $K$-migration is proportionally less than the shadow L-migration.

Production effects. Combining the shadow-migration insight and Rybczynski logic, it is intuitive that offshoring's general equilibrium incidence on production are ambiguous in sign and depend upon the relative shadow migration of $L$ and $K$. Solving (12) for the post-offshoring production and using (5), the production effects of offshoring are:

$$
\left[\begin{array}{c}
X_{O} \\
Y_{O}
\end{array}\right]=\left[\begin{array}{c}
X \\
Y
\end{array}\right]+\mathbf{A}^{-1}\left[\begin{array}{c}
\Delta L \\
\Delta K
\end{array}\right], \quad\left[\begin{array}{c}
X_{O}^{*} \\
Y_{O}^{*}
\end{array}\right]=\left[\begin{array}{c}
X^{*} \\
Y^{*}
\end{array}\right]-\left(\frac{1}{\gamma}\right) \mathbf{A}^{-1}\left[\begin{array}{c}
\Delta L \\
\Delta K
\end{array}\right]
$$

where $X, Y, X^{*}$ and $Y^{*}$ are defined in (5). This shows, as anticipated by the Rybczynski logic, that Home $X$ output rises if $\Delta K / \Delta L$ is lower than $\kappa_{Y}$ and Home $Y$ output either rises less or falls. ${ }^{9}$ The necessary and sufficient condition of $Y$ output to fall is $\Delta K / \Delta L<\kappa_{X}$. From (16), the change in Foreign product has the opposite sign as the change in Home production effects, but the magnitudes are mitigated by the Foreign technological disadvantage $\gamma$. Specifically, $\Delta X^{*}=-\Delta X / \gamma$ and $\Delta Y^{*}=-\Delta Y / \gamma$, where $\Delta$ indicates change. The various outcomes are depicted in the left-panel of Figure 1 . The usual Jonesian magnification effects are in operation. ${ }^{10}$ To summarise:

Proposition 2: Offshoring can be viewed as shadow migration of Foreign L and K. The impact on Home production follows a Rybczynski-like pattern, if offshoring implies a very unbalanced ratio of $K$ versus $L$ shadow migration, but the output of both sectors may rise if the amounts of $\mathrm{L}$ and $\mathrm{K}$ shadow migration are fairly similar. The exact limits are shown in Figure 1. Standard Jonesian magnification effects occur.

Wage effects. Combing the cost-savings aspect of the shadow-migration insight with StolperSamuelson logic, it is intuitive that the general equilibrium incidence of offshoring on wages is ambiguous. For example, if offshoring leads to a great deal of cost-saving in the $L$-intensive sector which acts like a rise in the price of $X$ as per (14) - then $w$ rises and $r$ tends to fall. More precisely, we solve (14) for the post-offshoring wages:

\footnotetext{
${ }^{9}$ The solutions are $\Delta X \equiv X_{O^{-}} X=\left(\kappa_{Y}-\Delta K / \Delta L\right) \Delta L / a_{L X} /\left(\kappa_{Y}-\kappa_{X}\right)$ and $\Delta Y \equiv Y_{O^{-}} Y=\left(\Delta K / \Delta L-\kappa_{X}\right) \Delta L / a_{L Y} /\left(\kappa_{Y}-\kappa_{X}\right)$. Since the denominators are positive, the sign of the production effect turns on the difference between $\Delta K / \Delta L$ and the $\kappa^{2} \mathrm{~s}$.

${ }^{10}$ For example, $\Delta X / X=\left\{(\Delta L / L) /\left(1-k / \kappa_{Y}\right)-(\Delta K / K) /\left(\kappa_{Y} / k-1\right)\right\}$ and $k / \kappa_{Y}<1$ since both economies' product is diversified.
} 


$$
\left[\begin{array}{c}
w_{O} \\
r_{O}
\end{array}\right]=\left[\begin{array}{c}
w \\
r
\end{array}\right]+\left(\mathbf{A}^{\mathbf{T}}\right)^{-1}\left[\begin{array}{c}
S_{X} \\
S_{Y}+\Delta p
\end{array}\right], \quad\left[\begin{array}{c}
w_{O}^{*} \\
r_{O}^{*}
\end{array}\right]=\left[\begin{array}{c}
w^{*} \\
r^{*}
\end{array}\right]+\frac{1}{\gamma}\left(\mathbf{A}^{\mathbf{T}}\right)^{-1}\left[\begin{array}{c}
0 \\
\Delta p
\end{array}\right]
$$

where $\Delta p \equiv p_{O}-p$, and $w, r, w^{*}$ and $r^{*}$ are defined in (5). This shows that the wage of Home $L$ workers rises (controlling for terms of trade effects $\Delta p$ ), if and only if the cost-savings is sufficiently greater in the $L$-intensive sector than in the $K$-intensive sector. Using well-know solutions for (17), the precise necessary and sufficient condition is $S_{X} / S_{Y}>a_{K X} / a_{K Y}$. Additionally, $r$ rises less or actually falls. The necessary and sufficient condition for $r$ to fall (controlling for terms of trade effects), is that the ratio of cost-savings exceeds the ratio of $L$-input coefficients, $S_{X} / S_{Y}>a_{L X} / a_{L Y}$. If the cost-savings ratio lies between the capital and labour ratios, then both wages may rise (an 'anti-Stolper-Samuelson' effect). Figure 1 illustrates the possibilities. The usual Jonesian magnification effects are in operation.
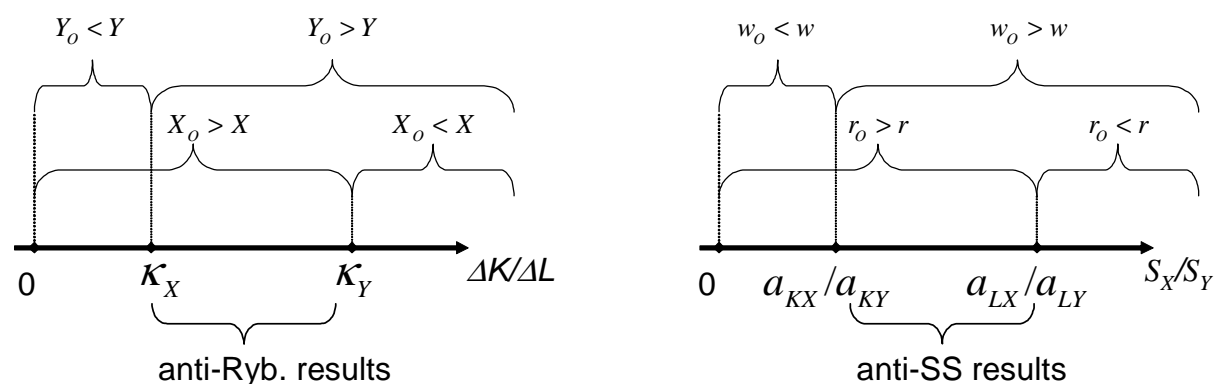

Figure 1: Shadow-migration, cost-savings, and offshoring's production and wage effects

Apart from possible terms-of-trade effects, there is no change in the foreign wages as Foreign goods are produced with the unchanged Foreign technology. ${ }^{11}$ To summarise:

Proposition 3: Offshoring raises the real wage of Home $L$-workers if the offshoring implies cost savings that are sufficiently larger in the $L$-intensive sector than in the $K$-intensive sector; the real wage of $K$-workers rises less or actually falls; it falls if the cost-savings are sufficiently skewed towards the $L$-intensive sector. The precise necessary and sufficient conditions are illustrated in Figure 1. Apart from terms of trade effects, wages of Foreign $L$ - and $K$-workers are unaffected.

Notice that shadow migration can widen or narrow the international wage gap for each type of labour, so offshoring may increase or decrease the pressure for real migration. In this sense, shadow migration need not be a substitute for real migration.

Rent allocation. The cost savings arises from the use of Home's superior technology with Foreign's cheap labour. This creates rents (Foreign workers in the offshoring sector are paid their reservation wage rather than their marginal product) that accrue entirely to Home in the services-version of our offshoring model. The sectoral bias in the cost-savings determines how much of these rents go to Home $L$-workers as opposed to Home $K$-workers. This can be seen explicitly by writing (17) in terms of the Home-Foreign wage gaps using the definitions of the $S$ 's in (14):

$$
\left[\begin{array}{c}
w_{O}-w \\
r_{O}-r
\end{array}\right]=\left(\mathbf{A}^{\mathbf{T}}\right)^{-1} \mathbf{A}_{1}^{\mathbf{T}}\left[\begin{array}{c}
w_{O}-w_{O}^{*} \\
r_{O}-r_{O}^{*}
\end{array}\right]+\left(\mathbf{A}^{\mathbf{T}}\right)^{-1}\left[\begin{array}{c}
0 \\
\Delta p
\end{array}\right]
$$

\footnotetext{
${ }^{11}$ If offshoring involves a relatively large amount of shadow $L$-migration versus shadow $K$-migration, the price of the $L$ intensive goods will fall, as per (15); this implies a negative terms of trade effect for Foreign, so Foreign $L$-workers would lose and Foreign $K$-workers would gain according to standard Stolper-Samuelson reasoning.
} 
Using the definitions of $S_{X}$ and $S_{Y}$, this shows that the division of rents between Home $L$ - and $K$ workers depends upon the relative labour savings in the $X$ and $Y$ sectors.

Extreme offshoring. One interesting special case is where the coordination costs for all tasks are zero (all $\chi$ 's are unity). In this case, all tasks are offshored and Home's superior technology completely displaces Foreign technology (all Foreign labourers work in the offshoring sector). The outcome is exactly like a technology transfer from Home to Foreign that brings the Foreign economy to the technology frontier. In this extreme case, Home wages are unchanged (controlling for terms of trade effects) but Foreign wages rise to Home levels. This tells us that the wage-offshoring relationship is thus non-monotonic. A modest lowering of coordination costs produces offshoring that raises advanced-nation real incomes (as per Proposition 1), but a very large reduction could return them to the pre-offshoring level, while raising the backward nation's factor prices to those of the advanced nation.

Inter-industry and intra-industry trade effects. Since offshoring changes the Home technology matrix but does not affect Foreign's, we can no longer transform the equilibrium into free trade among nations with identical technology using the effective labour concept. This means that much of the elegance of the $\mathrm{HO}$ trade equation (7) disappears with offshoring, except in special cases. In particular, Home firms face the technology matrix $\mathbf{A}-\mathbf{A}_{\mathbf{1}}$ while Foreign firms continue to face $\gamma \mathbf{A}$.

Home imports of $X$ are (1- $\alpha$ ) times its GDP minus its production of $X$. In the offshoring equilibrium, $M_{X O}=(1-\alpha) E_{O}-X_{O}$, so we can express the change in imports in terms of the change in Home's GDP and its production of X, i.e. $M_{X O}-M_{X}=(1-\alpha) \Delta E-\Delta X$. Since offshoring's impact on $E$ is driven by factor price changes - and thus $S_{X}$ and $S_{Y}$ as per (17) - while its impact on $X$ is driven by $\Delta L$ and $\Delta K$ as per (16), offshoring changes the pattern of trade in final goods (apart from knife-edge cases). For example, if the shadow migration is heavily biased towards $K$ (so the impact on $X$ is negative) and the per-unit cost-saving is heavily biased towards $Y$ (so the wage of Home's abundant factor rises) then Home's imports of $X$ will rise. More precisely, we calculate $\Delta E$ (which equals $L \Delta w+K \Delta r$ ) from (17) and $\Delta X$ from (16) to get:

$$
M_{X O}-M_{X}=(1-\alpha)\left[\begin{array}{c}
L \\
K
\end{array}\right]^{\mathrm{T}}\left(\mathbf{A}^{\mathrm{T}}\right)^{-1}\left[\begin{array}{c}
S_{X} \\
S_{Y}+\Delta p
\end{array}\right]-\left(\kappa_{Y}-\frac{\Delta K}{\Delta L}\right) \frac{a_{L Y} \Delta L}{\operatorname{det}(\mathbf{A})}
$$

Plainly this depends upon the sectoral cost-saving (the $S$ 's) and shadow migration, $\Delta K$ and $\Delta L$, in complex ways. Thus, except in knife-edge cases offshoring alters the pattern of trade in final goods. To summarise:

Proposition 4: Offshoring is a 'source of comparative advantage' in that it alters the pattern of trade in final goods. For instance, if Home and Foreign have identical endowments ratios there would be no HO motive for trade without offshoring, but trade in final goods can arises due to the 'shadow migration' associated with offshoring.

Intra-industry trade arises with offshoring if statisticians classify the output of tasks $X 1$ and $Y 1$ as $X$ sector and $Y$-sector trade respectively. Home imports the fruit of tasks $X 1$ and $Y 1$. Since Home also imports either $X$ or $Y$ final goods (except in knife-edge cases), intra-industry trade must arise. To summarise:

Proposition 5: Offshoring typically creates intra-industry trade since Home imports the fruit of the offshored task $X 1$ and $Y 1$ and is, typically, a net exporter of either $X$ or $Y$ even if Home and Foreign have identical factor endowments. 
A standard measure of the volume of intra-industry trade is the 'overlap' of a country's import and exports within a given sector. Denoting 'IIT' as our measure of intra-industry trade and writing Home's imports of tasks in sector $J_{O}=\left(X_{O}\right.$ or $\left.Y_{O}\right)$ as $M_{J}^{\text {Tasks }} \equiv\left(a_{L J 1} w^{*}+a_{K J 1} r^{*}\right) J_{O}$ :

$$
I I T= \begin{cases}2 M_{Y}^{\text {Tasks }} & \text { if } M_{X O}<0 \\ 2 M_{X}^{\text {Tasks }} & \text { if } M_{Y O}<0 \\ M_{X}^{\text {Tasks }}+M_{Y}^{\text {Tasks }} & \text { if } M_{Y O}, M_{X O}<0\end{cases}
$$

\subsection{Trade in tasks and the 4 theorems}

The effective Factor Price Equalisation theorem described above involved a pre- and post-trade comparison of wages in the absence of offshoring. Offshoring, in general, breaks the effective factor price equalisation since it changes Home wages. In other words, if a nation engaged in offshoring but the econometrician ignored it, a test of the effective factor price equalisation theorem would fail. Moreover, it would be easy to confuse the direction of causality. Offshoring creates extra trade and it widens the international wage gap (for at least one type of labour and possibly both as per Proposition 1). Thus, empirical researchers might mistakenly attribute the gap-widening to the extra trade while in truth the two were created by a third cause - the technology-transfer embodied in offshoring.

The Heckscher-Ohlin theorem links trade in goods to relative factor endowments. The HeckscherOhlin theorem does not necessarily hold when there is free trade and offshoring. For instance, if nations have identical factor endowment ratios, free trade and offshoring would result in inter-industry trade when the $\mathrm{HO}$ theorem would predict none. If the econometrician tested the HO theorem ignoring offshoring, the data might contradict the sign predictions of the HO theorem (the labour abundant nation might export the $K$-intensive good on net as per Proposition 4, a Leontief-like paradox). If the econometrician used sector average factor intensities (e.g. $a_{L X}$ and $a_{K X}$ ) to evaluate the factor content of the trade in tasks $X 1$ and $Y 1$ as well as the trade in final goods, the volume predictions of the HO theorem would be violated even if the sign predictions were correct. Depending upon the factor intensity of the offshored tasks, the data might be marked by a 'missing trade' paradox, i.e. show less net trade than predicted by the HO theorem, but equally well there might be too much net trade.

The correct version of the HO theorem in our model is rather involved. Since Home GDP is $X_{O}+p_{O} Y_{O}-w_{O}^{*} \Delta L-r_{O}^{*} \Delta K$, namely the output of final goods less the cost of imported intermediates, we can use the manipulations leading to (7) to write Home imports of $X$ as:

$$
M_{X O}=\frac{\alpha L_{O}}{a_{L X}}\left(\frac{k_{O}-\tilde{k}_{O}^{w}}{\tilde{k}_{O}^{w}-\kappa_{X}}\right)-(1-\alpha)\left(w_{O}^{*} \Delta L+r_{O}^{*} \Delta K\right)
$$

The first term is isomorphic to the standard HO theorem formulation as in (7), except we use the shadow rather than the actual relative endowments (in effective units). The second term is proportional to two endogenous quantities that might be observable - the total wage bill in the offshoring sector in Foreign, and the value of Home's imports of intermediates (all in terms of the numeraire). The closed form solution for $(1-\alpha)\left(w^{*} \Delta L+r^{*} \Delta K\right)$, employing the definitions of $\Delta K$ and $\Delta L$, (17) and (16), is:

$$
w_{O}^{*} \Delta L+r_{O}^{*} \Delta K \equiv\left[\begin{array}{ll}
w_{O}^{*} & r_{O}^{*}
\end{array}\right]\left[\begin{array}{c}
\Delta L \\
\Delta K
\end{array}\right]=\gamma^{-1}\left[\left(\mathbf{A}^{\mathbf{T}}\right)^{-1}\left[\begin{array}{c}
1 \\
p_{O}
\end{array}\right]\right]^{\mathbf{T}} \mathbf{A}_{1} \mathbf{A}^{-1}\left[\begin{array}{c}
L_{O} \\
K_{O}
\end{array}\right]
$$

Combining these elements, the HO theorem with offshoring can be written as

$$
M_{X O}=\frac{\alpha L_{O}}{a_{L X}}\left(\frac{k_{O}-\tilde{k}_{O}^{w}}{\tilde{k}_{O}^{w}-\kappa_{X}}\right)-\frac{1-\alpha}{\gamma}\left[\left(\mathbf{A}^{\mathbf{T}}\right)^{-1}\left[\begin{array}{c}
1 \\
p_{O}
\end{array}\right]\right]^{\mathbf{T}} \mathbf{A}_{1} \mathbf{A}^{-1}\left[\begin{array}{c}
L_{O} \\
K_{O}
\end{array}\right]
$$


where $p_{O}$ is defined in (15). Plainly this is far more complex that the usual HO theorem. The reason is that offshoring alters the relative technology matrices in ways that prevent us from using the effectivelabour concept to cleanly restate the equilibrium as trade between nations with identical technology.

The Stolper-Samuelson theorem is a partial equilibrium result linking factor and goods prices. In the partial equilibrium spirit, we take the extent of offshoring - as measured by $S_{X}$ and $S_{Y}$ - to be exogenous when formulating the equivalent theorem for the case of free trade in tasks and goods. Inspection of (17) shows that the theorem would be unaltered for Foreign, but the transmission of changes in $p$ to Home $w$ and $r$ is altered by the $S_{X}$ and $S_{Y}$ terms. Using (17), the theorem's analogue in our model is:

$$
\left.\frac{d w_{O} / w_{O}}{d p_{O} / p_{O}}\right|_{S_{X}, S_{Y}}=\frac{-p_{O}}{a_{K Y} / a_{K X}-p_{O}}\left(\frac{w}{w_{O}}\right),\left.\quad \frac{d r_{O} / r_{O}}{d p / p}\right|_{S_{X}, S_{Y}}=\frac{p_{O}}{p_{O}-a_{L Y} / a_{L X}}\left(\frac{r}{r_{O}}\right)
$$

Comparing this to (8), we see that the impact on $w$ would be dampened (less negative) and the impact on $r$ would be magnified (more positive), if and only if $w_{O}$ rises and $r_{O}$ falls with offshoring (controlling for terms of trade effects). As we know from the discussion above, a necessary condition for this to be the case is that the relative cost saving is skewed towards the $L$-intensive sector so that $S_{X} / S_{Y}>a_{L X} / a_{L Y}$, as per Figure 1.

The Rybczynski theorem analogue with trade in tasks is (taking the extent of shadow migration as given):

$$
\left.\frac{d X_{O} / X_{O}}{d L_{O} / L_{O}}\right|_{\Delta L, \Delta K}=\frac{\kappa_{Y}}{\kappa_{Y}-k_{O}}\left(\frac{X}{X_{O}}\right),\left.\quad \frac{d Y_{O} / Y_{O}}{d L / L}\right|_{\Delta L, \Delta K}=\frac{-\kappa_{X}}{k_{O}-\kappa_{X}}\left(\frac{Y}{Y_{O}}\right)
$$

where $k_{O} \equiv(K+\Delta K) /(L+\Delta L)$. Comparison of this and (9) provides two main results. First, under the assumption that offshoring does not reverse the ranking of relative factor intensities, the proportional increase in $X$ from a given proportional increase in $L$ would be smaller under trade in goods only, but the drop in $Y$ production would be more marked, if and only if $X_{\mathrm{O}}>X$ and $Y_{\mathrm{O}}<Y$; for these conditions to hold, it is sufficient that $\kappa_{X}>\Delta K / \Delta L$. If $\Delta K / \Delta L>\kappa_{Y}$, then the proportional increase in $X$ is more marked and the proportional drop of $Y$ would be dampened. Second, if as a result of offshoring $X$ becomes capital intensive, then the output of $X$ decreases as a result of an increase in $L$ by the usual Rybczynski logic. To summarise:

Proposition 6: Offshoring alters the four HO theorems. An econometrician who tested the HO theorem's sign and volume predictions ignoring offshoring would reject the theorem even though a modified form the HO theorem holds. The same can be said for the factor price equalisation theorem since the extra trade induced by offshoring tends to widen international factor price gaps. The Stolper-Samuelson and Rybczynski theorems would also appear to be rejected in their strict forms although properly modified versions of the theorems hold.

\subsection{Integrating special cases in the literature}

The fragmentation/offshoring literature has focused on special cases. Many of the papers assume that offshoring occurs in only a single sector while others present cases where offshoring only involves a single factor. Here we illustrate how our offshoring model can integrate the various cases. To keep our synthesis manageable, we limit our focus to Home wage effects and ignore terms of trade effects.

From (17):

$$
\Delta w=\frac{a_{K Y} S_{X}-a_{K X} S_{Y}}{\operatorname{det}(\mathbf{A})}, \quad \Delta r=\frac{a_{L X} S_{Y}-a_{L Y} S_{X}}{\operatorname{det}(\mathbf{A})}
$$


In the papers that assume only one sector experiences fragmented/offshoring (so $S_{X}$ or $S_{Y}$ is zero), offshoring that acts like sector-specific Home technical progress, so the wage changes (ignoring terms of trade effects) are simple and "Jones ambiguity" (see Introduction) arises. If offshoring/fragmentation occurs only in the unskilled-labour intensive $X$-sector, $S_{Y}=0$ and Home unskilled wages rise, but $w$ falls if offshoring occurs only in the $Y$-sector. Likewise, $r$ rises and $w$ falls if the offshoring occurs only in the skilled labour intensive sector.

In papers where offshoring involves only one factor, e.g. GRH (2006a), offshoring acts like a factorspecific cost savings and the well-known GRH result that offshoring unambiguous boosts the wage of workers' whose jobs are offshored (controlling for terms of trade effects) can arise. GRH (2006a) assume production functions where each task uses only $L$-labour or only $K$-labour and they undertake most of the analysis assuming that only $L$-tasks are offshored. ${ }^{12}$ In this case, $S_{X}=a_{L X 1}\left(w_{O}-w_{O}^{*}\right)$ and $S_{Y}=a_{L Y 1}\left(w_{O}-w_{O}^{*}\right)$, so:

$\Delta w=\frac{a_{K Y} a_{L X 1}-a_{K X} a_{L Y 1}}{\operatorname{det}(\mathbf{A})}\left(w_{O}-w_{O}^{*}\right), \quad \Delta r=\frac{\left(a_{L Y 1} / a_{L Y}\right)-\left(a_{L X 1} / a_{L X}\right)}{\operatorname{det}(\mathbf{A})} a_{L Y} a_{L X}\left(w_{O}-w_{O}^{*}\right)$

Due to GRH normalisations involving the size of tasks and the equality of offshoring costs across sectors, the numerator of $\Delta r$ is zero, while $\Delta w$ is positive. ${ }^{13}$ GRH (2006b) also consider the case where tasks that involve only $K$-labour can also be offshored and this case $S_{X}$ and $S_{Y}$ regain their general formulation as in (14), so the Jones ambiguity is restored as per Proposition 3.

\section{MANUFACTURING TASK OFFSHORING}

In the previous section, all output of the offshored sector was sold to Home even though offshored production units produce tasks $X 1$ and $Y 1$ at a lower cost than the Foreign producers. Here we allow local sales of $X 1$ and $Y 1$. For the sake of terminological clarity, we refer to this case (where the $\zeta$ 's are zero) as the 'manufacturing goods case' even though it could apply to some types of services.

When inter-firm coordination costs $\zeta(X 1)$ and $\zeta(X 1)$ are zero, the offshoring Home firms would also supply $X 1$ and $Y 1$ to Foreign producers. This would change the pricing and employment equations to:

$$
\left[\begin{array}{c}
1+S_{X} \\
p_{O}+S_{Y}
\end{array}\right]=\mathbf{A}^{\mathrm{T}}\left[\begin{array}{c}
w_{O} \\
r_{O}
\end{array}\right],\left[\begin{array}{c}
1+S_{X}^{*} \\
p_{O}+S_{Y}^{*}
\end{array}\right]=\gamma \mathbf{A}^{\mathbf{T}}\left[\begin{array}{c}
w_{O}^{*} \\
r_{O}^{*}
\end{array}\right], \quad\left[\begin{array}{c}
L+\Delta L \\
K+\Delta K
\end{array}\right]=\mathbf{A}\left[\begin{array}{c}
X_{O} \\
Y_{O}
\end{array}\right],\left[\begin{array}{c}
L^{*}-\Delta L^{*} \\
K^{*}-\Delta K^{*}
\end{array}\right]=\gamma \mathbf{A}\left[\begin{array}{c}
X_{O}^{*} \\
Y_{O}^{*}
\end{array}\right]
$$

where the subscript ' $O$ ' indicate the new offshoring equilibrium (i.e. we 'reset' the notation, so the value of these endogenous variables differs from those in previous sections), and

$$
\left[\begin{array}{c}
S_{X} \\
S_{Y}
\end{array}\right] \equiv \mathbf{A}_{1}^{\mathrm{T}}\left[\begin{array}{c}
w_{O}-w_{O}^{*} \\
r_{O}-r_{O}^{*}
\end{array}\right], \quad\left[\begin{array}{c}
S_{X}^{*} \\
S_{Y}^{*}
\end{array}\right] \equiv(\gamma-1) \mathbf{A}_{1}^{\mathrm{T}}\left[\begin{array}{c}
w_{O}^{*} \\
r_{O}^{*}
\end{array}\right], \quad\left[\begin{array}{c}
\Delta L \\
\Delta K
\end{array}\right] \equiv \mathbf{A}_{1}\left[\begin{array}{c}
X_{O} \\
Y_{O}
\end{array}\right], \quad\left[\begin{array}{c}
\Delta L^{*} \\
\Delta K^{*}
\end{array}\right] \equiv(\gamma-1) \mathbf{A}_{1}\left[\begin{array}{c}
X_{O}^{*} \\
Y_{O}^{*}
\end{array}\right]-\left[\begin{array}{c}
\Delta L \\
\Delta K
\end{array}\right]
$$

\footnotetext{
${ }^{12}$ GRH (2006a) focuses exclusively on the case where only tasks involving $L$ can be offshored; GRH (2006b) also considers the possibility that tasks involving $K$ can be also be offshored. The main restriction in their formal analysis in both papers is that every task is performed only by $L$ or only by $K$.

${ }^{13}$ GRH (2006b) normalize the measure of a task so that $L$-tasks in both industries all have the same unit input coefficients, i.e. $a_{L X I}=a_{L Y I}$, in our notation. They also assume that the offshoring cost for the tasks that have been thus normalised are identical across sectors (i.e. $t_{x}(i)=t_{y}(i)=t(i)$ in their notation). This interaction between the normalisation of task 'sizes' (formally, their measure) within each sector and the cross-sector assumption on offshoring costs implies that the labour cost-saving in both sectors is proportional to the pre-offshoring unit-labour input coefficient, which, in our notation implies $a_{L X I} / a_{L X}=a_{L Y I} / a_{L Y}$. Footnote 12 in GRH (2006b) suggests that $a_{L X I}=a_{L Y I}$ could be relaxed by allowing more general substitution among tasks but the mapping to offshoring costs in this a case is not made explicit.
} 
Note that the $S$ 's and $\Delta$ 's are different from the previous section.

Solving (26) for wages, using (5) for $w, r, w^{*}$ and $r^{*}$ :

$$
\left[\begin{array}{c}
w_{O} \\
r_{O}
\end{array}\right]=\left[\begin{array}{c}
w \\
r
\end{array}\right]+\left(\mathbf{A}^{\mathbf{T}}\right)^{-1}\left[\begin{array}{c}
S_{X} \\
S_{Y}+\Delta p
\end{array}\right], \quad\left[\begin{array}{c}
w_{O}^{*} \\
r_{O}^{*}
\end{array}\right]=\left[\begin{array}{c}
w^{*} \\
r^{*}
\end{array}\right]+\frac{1}{\gamma}\left(\mathbf{A}^{\mathbf{T}}\right)^{-1}\left[\begin{array}{c}
S_{X}^{*} \\
S_{Y}^{*}+\Delta p
\end{array}\right]
$$

where $\Delta \mathrm{p}$ denotes $p_{O}-p$ as before. Two aspects of this expression are noteworthy. First, the expression for Home factor prices is isomorphic to (17) so our analysis in the service-offshoring case in the previous section also applies in this model extension (although the exact value of $S_{X}$ and $S_{Y}$ may change since the Foreign factor prices can be different). Second, the wages of Foreign workers also benefit from the cost-savings induced by the offshoring-linked technology transfer (the exact persector cost saving is given by $S_{X}^{*}$ and $\left.S_{Y}^{*}\right) .{ }^{14}$ Moreover, the form of the Foreign wage changes in (27) are isomorphic to those of Home. Consequently, all the detailed analysis in the previous section relating the cost-savings to the wage effects (e.g. Proposition 3 and Figure 1) is applicable to the impact of offshoring on Foreign wages with $S_{X}^{*}$ and $S_{Y}^{*}$ substituted for $S_{X}$ and $S_{Y}$.

Solving (26) for production, using (5) for $X, Y, X^{*}$ and $Y^{*}$ :

$$
\left[\begin{array}{l}
\Delta X \\
\Delta Y
\end{array}\right]=(\mathbf{A})^{-1}\left[\begin{array}{c}
\Delta L \\
\Delta K
\end{array}\right], \quad\left[\begin{array}{l}
\Delta X^{*} \\
\Delta Y^{*}
\end{array}\right]=\frac{1}{\gamma}(\mathbf{A})^{-1}\left[\begin{array}{c}
\Delta L^{*} \\
\Delta K^{*}
\end{array}\right]
$$

Qualitatively, the impact on Home production is the same as in the service-offshoring case in the previous section. The impact on Foreign production, however, is qualitatively different and the shadow migration interpretation is less clear-cut (note in particular that the sign of $\Delta \mathrm{L}^{*}$ and $\Delta \mathrm{K}^{*}$ is now ambiguous, though effective world endowments of $L$ and $K$ are unambiguously larger with offshoring, i.e. $\tilde{L}_{O}^{w}>\tilde{L}^{w}$ and $\tilde{K}_{O}^{w}>\tilde{K}^{w}$. In the service-offshoring case, Home offshored technology was used only for Home production, so the Foreign labour employed in the offshoring sector was diverted from Foreign production and this meant that the Foreign production change was proportional to the Home production effect but of the opposite sign (e.g. $\left.\Delta X=-\Delta X^{*} / \gamma\right)$. Here the tech-transfer embodied in offshoring tends to stimulate Foreign production, so this simple proportionality breaks down. Nevertheless, the basic analysis of production effects for Foreign follows the Proposition 2 and Figure 1 reasoning (held for Home) with $\Delta X^{*}$ and $\Delta Y^{*}$ substituted for $\Delta X$ and $\Delta Y$.

Since the trade effects follow from the production and factor price changes, as per the reason surrounding Proposition 4 and 5, it is clear that offshoring in the goods-case at hand will also be a source of comparative advantage and intra-industry trade.

\section{EXTENDING THE BASIC MODEL}

In this section, we extend the basic trade-in-tasks model in two directions. First, we allow for Ricardian differences among nations and show that this can result in the two-way offshoring that is common among OECD nations (Amiti and Wei 2005). Second, we show that the basic analysis in Section 3 goes through in a simple Helpman-Krugman trade model. This may be useful since some of the coordination-cost assumptions in our offshoring model fit more naturally in setting where firms produce differentiated product (and thus naturally have differentiated inputs).

\footnotetext{
14 There is a crucial difference, though, between the factor price effects on Home versus Foreign labour. For Home labour, it is rents that generates the cost-savings (i.e. the fact that Foreign workers are paid less than their marginal products); for Foreign labour, technology transfer is the source of the cost-savings.
} 


\subsection{Intra-industry two-way offshoring ${ }^{15}$}

To focus on the essential differences between trade in goods and tasks, it proved convenient to eliminate Ricardian motives for trade by assuming that the international technology differences were of the Hicks neutral type. One result of this assumption was that Foreign never offshored tasks to Home. The extensive empirical literature on fragmentation, however, documents the importance of two-way offshoring. Here we modify the basic model in a way that creates two-way, intra-industry offshoring in spirit akin to Davis (1995). We shall do so in a highly specific model. As the analysis above made clear, there are a wealth of cases that could be considered (e.g. various combinations of factor abundance and technology superiority, factor intensity of the offshored tasks, etc.). However it is not really necessary to formally consider all the cases. Most of the cases can be dealt with simply using the core intuition that trade in tasks can be viewed as 'shadow migration'.

We assume 'mirror image' Ricardian superiority. Home has inferior technology in tasks $X 3$ and $Y 3$, while Foreign has inferior technology in tasks $X 1$ and $Y 1$. The nations have identical technology in tasks $X 2$ and $X 3$. Moreover, we assume that the task-level technological advantages exactly offset each other so that the two nations have the same sector-level unit input coefficients. Formally, let the inputoutput matrices be $\mathbf{B} \equiv\left\{b_{i j}\right\}$ and $\mathbf{B}^{*} \equiv\left\{b_{i j}{ }^{*}\right\}, i=L, K$ and $j=X, Y$. We assume that the technological edges in tasks 1 and 3 are such that:

$b_{i j} \equiv a_{i j 1}+a_{i j 2}+\gamma_{3} a_{i j 3}, \quad b_{i j}^{*} \equiv \gamma_{1} a_{i j 1}+a_{i j 2}+a_{i j 3}, \quad b_{i j}=b_{i j}^{*}, \quad \gamma_{h}>1 ; \quad i=K, L, \quad j=X, Y, \quad h=1,3$

so $\mathbf{B} * \mathbf{B}$. Finally, we assume nations have the same factor endowment ratios.

Given the analysis above, the outcome without offshoring (i.e. trade in tasks) is obvious. The two nations have identical wages and do not trade with each other, i.e.:

$\left[\begin{array}{l}1 \\ p\end{array}\right]=\mathbf{B}^{\mathbf{T}}\left[\begin{array}{c}w \\ r\end{array}\right]=\mathbf{B}^{\mathbf{T}}\left[\begin{array}{c}w^{*} \\ r^{*}\end{array}\right] ; \quad\left[\begin{array}{l}L \\ K\end{array}\right]=\mathbf{B}\left[\begin{array}{l}X \\ Y\end{array}\right]=\mathbf{B}\left[\begin{array}{c}X * \\ Y^{*}\end{array}\right]=\left[\begin{array}{c}L^{*} \\ K^{*}\end{array}\right]$

Once we allow free offshoring - i.e. the coordination costs, the $\chi$ 's and the $\zeta$ 's, drop to unity - trade in tasks occurs. Specifically, Home's superior technology in tasks $X 1$ and $Y 1$ completely displaces Foreign's technology in these tasks while Foreign's superior technology in tasks $X 3$ and $Y 3$ completely displaces Home's technology. In this case, the offshoring (and the fact that tasks can be sold at arm's length among firms since the $\zeta$ 's are unity) imply that both nations move to the technology frontier. As a result, the pricing and production equations are:

$\left[\begin{array}{c}1 \\ p_{O}\end{array}\right]=\mathbf{A}^{\mathbf{T}}\left[\begin{array}{c}w_{O} \\ r_{O}\end{array}\right]=\mathbf{A}^{\mathbf{T}}\left[\begin{array}{c}w_{O}^{*} \\ r_{O}^{*}\end{array}\right] ; \quad\left[\begin{array}{c}L \\ K\end{array}\right]=\mathbf{A}\left[\begin{array}{c}X_{O} \\ Y_{O}\end{array}\right]=\mathbf{A}\left[\begin{array}{c}X_{O}^{*} \\ Y_{O}^{*}\end{array}\right]=\left[\begin{array}{c}L^{*} \\ K^{*}\end{array}\right]$

where the subscript ' $O$ ' indicates two-way offshoring equilibrium variables (i.e. we have 'reset' the notation so these endogenous variables differ from those in previous sections). Since $\mathbf{B}>\mathbf{A}$ (i.e. each $b_{i j}$ is larger than the corresponding $a_{i j}$ ), it is immediate from (29) and (30) that, first, the real reward of at least one factor of production has risen and, second, (world and domestic) production of at least one of the two final goods has risen. In symbols:

$$
\left[\begin{array}{c}
\Delta w \\
\Delta r
\end{array}\right]=\left[\mathbf{I}-\left(\mathbf{B}^{\mathbf{T}}\right)^{-1} \mathbf{A}^{\mathbf{T}}\right]\left[\begin{array}{c}
w_{O} \\
r_{O}
\end{array}\right]+\left(\mathbf{B}^{\mathbf{T}}\right)^{-1}\left[\begin{array}{c}
0 \\
\Delta p
\end{array}\right] ; \quad\left[\begin{array}{c}
\Delta X \\
\Delta Y
\end{array}\right]=\left[\mathbf{I}-\mathbf{B}^{-1} \mathbf{A}\right]\left[\begin{array}{c}
X_{O} \\
Y_{O}
\end{array}\right]
$$

where $\mathbf{I}$ is the identity matrix. The interpretation of this expression revolves around the same considerations as in Section 4.

\footnotetext{
${ }^{15}$ We would like to thank Toshi Okubo for providing the idea for this section.
} 
The production effects are simple to work out. The two-way offshoring is like 'shadow migration' but due to the symmetry we imposed, there is no net shadow migration, so there is no Rybczynski effect in either nation. By contrast, the move of both nations towards the technology frontier as a result of twoway offshoring will be isomorphic to a labour saving productivity improvement in both sectors in both nations. Given the ex ante symmetry of the nations at the sector level and the ex post symmetry of the nations at the task level, there is no trade in final goods either before or after free offshoring. With offshoring, all trade is intra-industry trade in tasks. If the tasks represent manufacturing stages, this would be parts and components trade. If they are service inputs, this would be intra-industry services trade. $^{16}$

\subsection{Offshoring in a Helpman-Krugman trade model}

A fact that has been well appreciated in the literature since Norman (1976) and Helpman and Krugman (1985) is that the basic HO results carry through unaltered in a Dixit-Stiglitz monopolistic competition setting provided that technologies are homothetic. ${ }^{17}$ Here we use this insight to show that the Section 3 analysis could easily be conducted in a monopolistic competition trade model setting. Such a setting has the merit of making firm-level variables better defined but the demerit of reducing comparability with the classic HO model.

The key to the Section 3 analysis lies in the pricing and employment equations and their restatement using the shadow migration insight. As is well known, the free-entry output of a typical variety under monopolistic competition (MC) with homothetic technologies, is parametrically fixed at $F(\sigma-1)$, where $F$ is the fixed entry cost and $\sigma$ is the elasticity of substitution. ${ }^{18}$ This implies that MC sectors display constant returns at the sector level (doubling sectoral output at equilibrium would require double the inputs). Equally well-known is Dixit-Stiglitz MC's constant mark-up pricing which makes prices proportional to marginal costs. These two facts imply that the MC pricing and employment equations differ only slightly from those of the HO model in Section 2. Specifically, assuming Dixit-Stiglitz competition in both sectors, the Home employment and pricing conditions are: ${ }^{19}$

$$
\left[\begin{array}{l}
L \\
K
\end{array}\right]=\left(\frac{\sigma}{\sigma-1}\right) \mathbf{A}\left[\begin{array}{l}
X \\
Y
\end{array}\right], \quad\left[\begin{array}{l}
1 \\
p
\end{array}\right]=\left(\frac{\sigma}{\sigma-1}\right) \mathbf{A}^{\mathrm{T}}\left[\begin{array}{l}
w \\
r
\end{array}\right]
$$

The Foreign pricing and employment conditions are isomorphic.

Since we have not specified units of $X, Y, L$ or $K$, we are free to now choose units such that the coefficient, $\sigma /(\sigma-1)$, is absorbed into the definitions of prices and endowments. With this, we have reduced the problem to the problem solved in Sections 3 (service-task case) and so can conclude that Propositions 1 to 6 also hold in this model.

\section{CONCLUDING REMARKS}

Our paper presents a simple model of offshoring that allows us to derive necessary and sufficient conditions are wage, production and trade effects of offshoring. The simplicity also allows us to re-

\footnotetext{
${ }^{16}$ This is consistent with the evidence in Schott (2004) insofar as we observe two-way trade at finely disaggregated levels and that the differences in productivity at the task level are re-interpreted as differences in the quality of the fruit of the task.

${ }^{17}$ A 'bundle' of $i$-sector factors uses $a_{L i}$ and $a_{K i}$ units of $L$ and $K$, respectively. The fixed cost involves $F$ bundles and the marginal cost involves 1 bundle in each sector $i=X, Y$.

${ }^{18}$ Let $x$ denote output and $v$ denote marginal cost. Free entry requires that the price, which is $v \sigma(\sigma-1)$, equals average cost, which equals $v(1+F / x)$, solving for $x$ yields the result in the text.

${ }^{19}$ The equilibrium output per firm in both sectors is $\mathrm{F}(\sigma-1)$, so the per-firm demand for factor bundles (including the demand for the fixed cost) is $x=F \sigma$. Since $X$-sector output is just $n x$ where $\mathrm{n}$ is the mass of $X$-firms, $n=X / F(\sigma-1)$, total $X$ sector labour demand is a $a_{L X}(F+x) n$, which equals $a_{L X}(\sigma(\sigma-1)) X$. Similar expressions hold for the other labour demands.
} 
formula the four classic $\mathrm{HO}$ theorems to account for trade in tasks (offshoring) as well as trade in goods. Our results can also be used to integrate the complex gallery of results derived in the extensive theoretical literature on offshoring/fragmentation. The key is that we view offshoring as "shadow migration' that brings with it cost-savings that act as technological changes. This permits us to use the elegant analysis of Jones (1965). The paper also shows that the basic model can easily be extended to account for two-way offshoring between similar nations. To bolster comparability between our results with offshoring and the four classic HO theorems, the bulk of our analysis is in a Walrasian setting, but we show that it applies equally in a simple monopolistic competition setting.

\section{REFERENCES}

Amiti, M. and S.J. Wei (2005), "Fear of Service Outsourcing: Is it Justified?”, Economic Policy, 20, pp. $308-348$.

Ando, M. and Kimura, F. (2005). The formation of international production and distribution networks in East Asia. In T. Ito and A. Rose (Eds.), International trade (NBER-East Asia seminar on economics, volume 14), Chicago: The University of Chicago Press. First version, NBER Working Paper 10167.

Batra, Raveendra N. and Francisco R. Casas (1973). "Intermediate Products and the Pure Theory of International Trade: A Neo-Hecksher-Ohlin Framework.” American Economic Review, Vol. 63, No. 3 (Jun., 1973), pp. 297-311

Blinder, Alan S., (2006), “Offshoring: The Next Industrial Revolution?” Foreign Affairs, 85:2, 113128.

Dallas, F. (2002), “Maquiladora Industry: Past, Present and Future.” Federal Reserve Bank of Dallas, El Paso Branch, Issue 2.

Davis, D. (1995). “Intra-Industry Trade: A Heckscher-Ohlin-Ricardo Approach,” Journal of International Economics, vol. 39, no. 3-4.

Deardorff, Alan V. (1998a). "Fragmentation in Simple Trade Models," RSIE Discussion Paper 422, University of Michigan, January 8, 1998. www.spp.umich.edu/rsie/workingpapers/wp.html

Deardorff, Alan V. (1998b). "Fragmentation across cones," RSIE Discussion Paper 427, Discussion Paper No. 427, August 7, 1998. www.spp.umich.edu/rsie/workingpapers/wp.html

Debande, Olivier (2006). "De-industrialisation," Volume 11, №1, European Investment Bank Papers. www.eib.org/attachments/general/events/02_Debande.pdf

Dixit, Avinash and Gene M. Grossman, (1982), "Trade and Protection with Multi-Stage Production," Review of Economic Studies, 49:4, 583-594.

Feenstra, R.C. and G.H. Hanson (1996), "Globalization, Outsourcing, and Wage Inequality", American Economic Review, 86, pp. 240-45.

Findlay, Ronald and Ronald W. Jones (2001). "Input Trade and the Location of Production," American Economic Review, American Economic Association, vol. 91(2), pages 29-33, May.

Findlay, Ronald, and Ronald Jones (2000). "Factor bias and technical progress," Economics Letters, Elsevier, vol. 68(3), pages 303-308, September.

Francois, Joseph (1990a). "Producer Services, Scale, and the Division of Labor," Oxford Economic Papers, vol. 42(4), pages 715-29.

Francois, Joseph (1990b). "Trade in Producer Services and Returns Due to Specialization under Monopolistic Competition," Canadian Journal of Economics, vol. 23(1), pages 109-24. 
Francois, Joseph (1990c). "Trade in Nontradables: Proximity Requirements and the Pattern of Trade in Services", Journal of Economic Integration, pp 31-46.

Geishecker, Ingo and Holger Gorg (2004). "International outsourcing and wages: Winners and losers," March 2004. Mimeo, www.etsg.org/ETSG2004/Papers/Geishecker.pdf

Grossman, G. and E. Rossi-Hansberg (2006a). "The Rise of Offshoring: It's Not Wine for Cloth Anymore," July 2006. Paper presented at Kansas Fed's Jackson Hole conference for Central Bankers. http://www.kc.frb.org/

Grossman, G. and E. Rossi-Hansberg (2006b). "Trading Tasks: A Simple Theory of Offshoring," August 2006. PDF file. www.princeton.edu/ grossman/offshoring.pdf

Helpman, E. and P. Krugman (1985). Market Structure and Foreign Trade, MIT Press.

Hummels, David \& Ishii, Jun \& Yi, Kei-Mu, 2001. "The nature and growth of vertical specialization in world trade," Journal of International Economics, Elsevier, vol. 54(1), pages 75-96.

Jones, R. and H. Kierzkowski (2000). “A Framework for Fragmentation,” Tinbergen Institute Discussion Paper, TI 2000-056/2.

Jones, R. and S. Marjit (1992). "International trade and endogenous production structures," in Economic Theory and International Trade, W. Neuefrind and R. Riezman (eds), SpringerVerlag.

Jones, R., H. Kierzkowski and G. Leonard (2002). "Fragmentation and intra-industry trade," in P. Lloyd and H Lee (eds), Frontiers of research in intra-industry trade, Palgrave Macmillian.

Jones, Ronald W. and Henryk Kierzkowski (1990): “The Role of Services in Production and International Trade: A Theoretical Framework", in Ronald Jones and Anne Krueger, eds., The Political Economy of International Trade, Basil Blackwell, Oxford.

Jones, Ronald W. and Henryk Kierzkowski (1998): "Globalization and the Consequences of International Fragmentation”, forthcoming in Rudiger Dornbusch, Guillermo Calvo and Maurice Obsfeld, eds., Money, Factor Mobility and Trade: The Festschrift in Honor of Robert A. Mundell, MIT Press, Cambridge, MA.

Kohler, W. (2004a). “Aspects of International Fragmentation," Review of International Economics 12 (5), 793-816.

Kohler, W. (2004b). "International outsourcing and factor prices with multistage production," The Economic Journal, 114 (494), C166-C185.

Markusen, James (2005). "Modeling the offshoring of white-collar services: from comparative advantage to the new theories of trade and fdi”. NBER Working Paper 11827.

Norman, V. (1976). "Product differentiation and trade," unpublished manuscript.

Schott, Peter (2004). "Across-product versus within-product specialisation in international trade." Quarterly Journal of Economics, Vol. 119, No. 2, 647-678.

Trefler, Daniel (1993). " International Factor Price Differences: Leontief was Right!" The Journal of Political Economy, Vol. 101, No. 6 (Dec., 1993), pp. 961-987.

Urata, S. (2001). "Emergence of FDI-trade nexus an economic growth in East Asia," in Stiglitz and Yussuf (eds) Rethinking the East Asian Miracle, Oxford University Press.

Venables, Anthony (1999). "Fragmentation and multinational production," European Economic Review 43, 935-945. 
Woodland, A. (1977). "Joint outputs, intermediate inputs and international trade theory," International Economic Review, 18, 3, pp 517-533.

Yi, K.M. (2003). "Can vertical specialization explain the growth of world trade?" Journal of Political Economy, 111(1), 52-102.

\section{APPENDIX: CLOSED FORM SOLUTIONS WITH OFFSHORING}

The closed-form solutions for wages and production with service offshoring are simple to derive but tend to be too complex to be revealing, so the text works with aggregates of parameters that are reflect to potentially observable quantities $-S_{X}, S_{Y}, \Delta L$, and $\Delta K$. Here we provide the closed-form solutions in matrix notation. These all follow from straightforward manipulation of (12) and the definitions of $S_{X}$, $S_{Y}, \Delta L$, and $\Delta K$. Foreign wages and Home production are simple to calculate since there is no interaction with the other pricing and employment equations:

$$
\left[\begin{array}{c}
\mathrm{w}_{O}^{*} \\
\mathrm{r}_{O}^{*}
\end{array}\right]=\gamma^{-1}\left(\mathbf{A}^{\mathrm{T}}\right)^{-1}\left[\begin{array}{c}
1 \\
\mathrm{p}_{\mathrm{O}}
\end{array}\right], \quad\left[\begin{array}{c}
\mathrm{X}_{\mathrm{O}} \\
\mathrm{Y}_{\mathrm{O}}
\end{array}\right]=\left(\mathbf{A}-\mathbf{A}_{1}\right)^{-1}\left[\begin{array}{c}
\mathrm{L} \\
\mathrm{K}
\end{array}\right]
$$

where $p_{O}$ is given in (15). Home wage and Foreign production vectors involve both pricing and employment condition and are thus more complex:

$$
\left[\begin{array}{c}
\mathrm{w}_{\mathrm{O}} \\
\mathrm{r}_{\mathrm{O}}
\end{array}\right]=\left(\mathbf{A}^{\mathrm{T}}-\mathbf{A}_{1}^{\mathrm{T}}\right)^{-1}\left(I-\frac{1}{\gamma} \mathbf{A}_{1}^{\mathrm{T}}\left(\mathbf{A}^{\mathrm{T}}\right)^{-1}\right)\left[\begin{array}{c}
1 \\
\mathrm{p}_{\mathrm{O}}
\end{array}\right], \quad\left[\begin{array}{c}
\mathrm{X}_{O}^{*} \\
\mathrm{Y}_{O}^{*}
\end{array}\right]=\frac{1}{\gamma} \mathbf{A}^{-1}\left(\left[\begin{array}{c}
\mathrm{L}^{*} \\
\mathrm{~K}^{*}
\end{array}\right]-\mathbf{A}_{1}\left(\mathbf{A}-\mathbf{A}_{1}\right)^{-1}\left[\begin{array}{c}
\mathrm{L} \\
\mathrm{K}
\end{array}\right]\right)
$$

